Document downloaded from:

http://hdl.handle.net/10251/153790

This paper must be cited as:

Rogina, A.; Ressler, A.; Matie, I.; Ferrer, G.; Marijanovic, I.; Ivankovic, M.; Ivankovic, H. (2017). Cellular hydrogels based on pH-responsive chitosan-hydroxyapatite system. Carbohydrate Polymers. 166:173-182. https://doi.org/10.1016/j.carbpol.2017.02.105

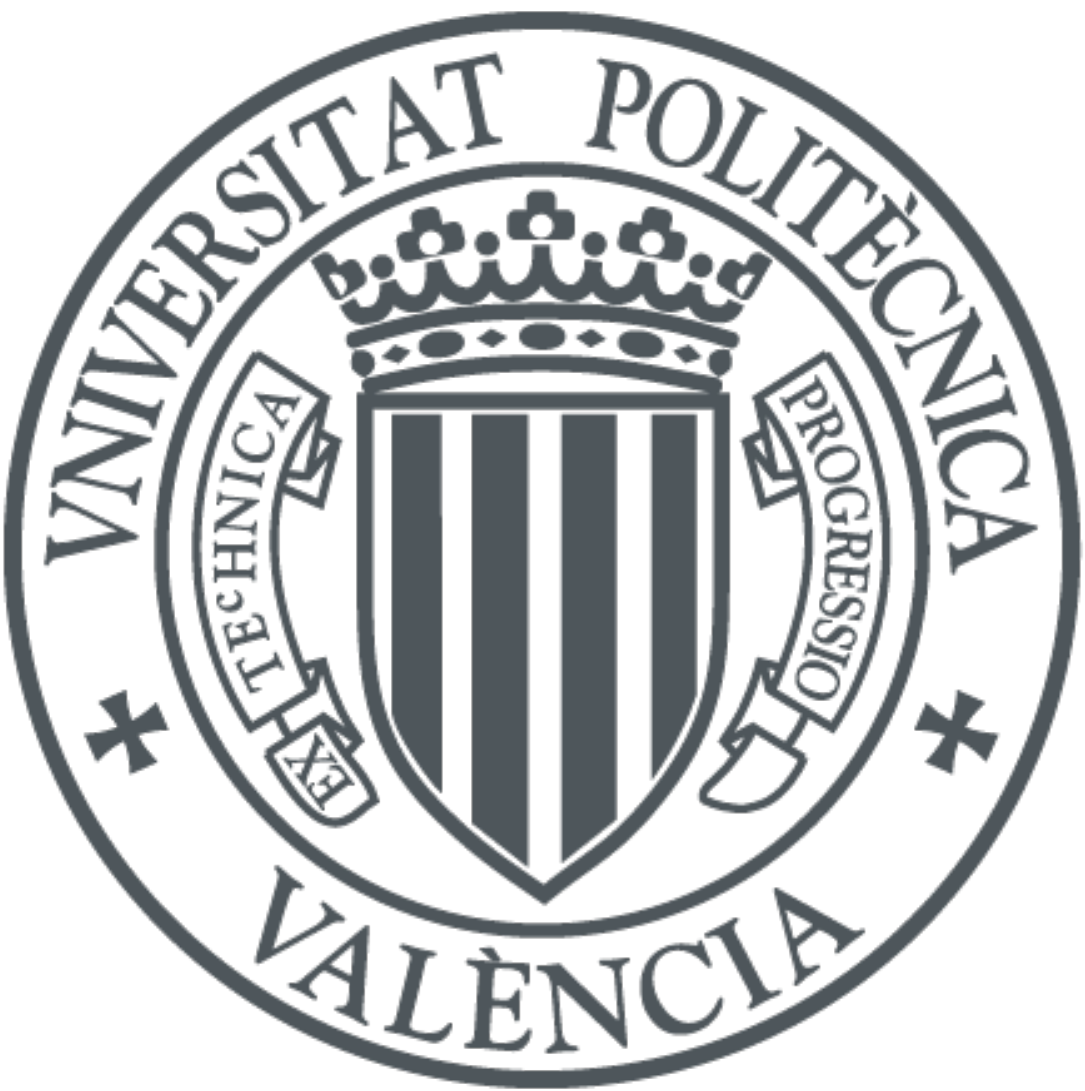

The final publication is available at

https://doi.org/10.1016/j.carbpol.2017.02.105

Copyright Elsevier

Additional Information 


\section{Cellular hydrogels based on pH-responsive chitosan-hydroxyapatite system}

Anamarija Rogina ${ }^{1}$, Antonia Ressler ${ }^{1}$, Igor Matić $^{2}$, Gloria Gallego Ferrer $^{3,4}$, Inga Marijanović ${ }^{2}$, Marica Ivanković ${ }^{1}$, Hrvoje Ivanković ${ }^{1}$

Corresponding author:

Anamarija Rogina

E-mail: arogina@fkit.hr

Tel: +38514597253

${ }^{1}$ Faculty of Chemical Engineering and Technology, University of Zagreb, HR-10001 Zagreb, Marulićev trg 19, p.p.177, Croatia

Co-authors:

Antonia Ressler

E-mail: aressler@fkit.hr

${ }^{1}$ Faculty of Chemical Engineering and Technology, University of Zagreb, HR-10001 Zagreb, Marulićev trg 19, p.p.177, Croatia

Igor Matić

E-mail: igor.matic@biol.pmf.hr

${ }^{2}$ Faculty of Science, University of Zagreb, HR-10001 Zagreb, Horvatovac102a, Croatia

Gloria Gallego Ferrer

E-mail: ggallego@ter.upv.es

${ }^{3}$ Centro de Biomateriales e Ingeniería Tisular, Universitat Politècnica de València, Camino de Vera s/n, 46022 Valencia, Spain

${ }^{4}$ Biomedical Research Networking centre in Bioengineering, Biomaterials and Nanomedicine (CIBER-BBN), Spain

Inga Marijanović

Email: ingam@biol.pmf.hr

${ }^{2}$ Faculty of Science, University of Zagreb, HR-10001 Zagreb, Horvatovac102a, Croatia

Marica Ivanković

E-mail: mivank@fkit.hr

${ }^{1}$ Faculty of Chemical Engineering and Technology, University of Zagreb, HR-10001 Zagreb, Marulićev trg 19, p.p.177, Croatia

Hrvoje Ivanković

E-mail: hivan@fkit.hr

${ }^{1}$ Faculty of Chemical Engineering and Technology, University of Zagreb, HR-10001 Zagreb, Marulićev trg 19, p.p.177, Croatia 


\title{
Highlights
}

- Physically crosslinked chitosan-HAp hydrogel was prepared by $\mathrm{NaHCO}_{3}$

- In situ apatite synthesis in chitosan ensured application of low $\mathrm{NaHCO}_{3}$ quantity

- The gelation time of chitosan-HAp/NaHCO 3 system is approximately 4 minutes

- Cells encapsulated within chitosan-HAp/ $/ \mathrm{NaHCO}_{3}$ show high viability

\section{Cellular hydrogels based on pH-responsive chitosan-hydroxyapatite system}

Anamarija Rogina, Antonia Ressler, Igor Matić, Gloria Gallego Ferrer, Inga Marijanović, Marica Ivanković, Hrvoje Ivanković

\begin{abstract}
The development of bioactive injectable system as cell carrier with minimal impact on viability of encapsulated cells represents a great challenge. In the present work, we propose a new pH-responsive chitosan-hydroxyapatite-based hydrogel with sodium bicarbonate $\left(\mathrm{NaHCO}_{3}\right)$ as the gelling agent. The in situ synthesis of hydroxyapatite phase has resulted in stable composite suspension and final homogeneous hydrogel. The application of sodium bicarbonate has allowed non-cytotoxic fast gelation of chitosan-hydroxyapatite within 4 minutes, and without excess of sodium ions concentration. Rheological properties of crosslinked hydrogel have demonstrated possible behaviour as 'strong physical hydrogel'. The live dead staining has confirmed good viability and dispersion, as well as proliferation of encapsulated cells by the culture time. Presented preliminary results show good potential of chitosan-hydroxyapatite/ $\mathrm{NaHCO}_{3}$ as a cell carrier, whose impact on the cell differentiation need to be confirmed by encapsulation of other cell phenotypes.
\end{abstract}

Keywords: chitosan, hydroxyapatite, $\mathrm{pH}$-responsive hydrogel, rheology, cell encapsulation.

\section{Introduction}

Cell-assisted therapy within scaffolds can allow faster tissue regeneration. Minimally invasive procedure used during such surgical therapy is a major advantage for medical care. The most widely investigated systems in such medical treatments are in situ gelling hydrogel-based matrices, since they have possibility to act as cell vehicles and do not require processing in 
specific geometrical shape. Injectable hydrogels hold great potential in bone defect reconstruction due to their ability to take the shape of the cavity and fill irregular defects, and to minimize the cell adhesion problems by simple incorporation into solution prior to injection (Bi, Cheng, Fan, \& Pei, 2010; Li et al., 2016). Hydrate nature of such gels allows mimicking the natural structure of the in vivo tissue environment, thus, they are ideal microenvironments for cell proliferation and differentiation (Kumar et al., 2014). The development of an ideal in situ forming injectable hydrogel has to meet several criteria including solubility in aqueous medium with gelation occurring under physiological conditions, no release of harmful byproducts upon gelation, and sufficiently rapid gelation rate for clinical efficacy (Tan \& Marra, 2010). Injectable hydrogels possess thermodynamically active functional groups sensitive to temperature, $\mathrm{pH}$ or irradiation stimuli resulting in physical or chemical sol-gel transition without harming the surrounding tissue (Amini \& Nair, 2012).

Chitosan-based injectable systems show great diversity in their composition which allows formation of chemical or physical hydrogels by UV irradiation, high temperature or higher $\mathrm{pH}$ (Yan et al., 2010; Cao et al., 2015; Ta, Dass \& Dunstan, 2008; Yasmeen, Lo, Bajrachary \& Roldo, 2014). The large focus has been made on chitosan injectable gels based on thermosensitive sol-gel transition initiated by $\beta$-glycerophosphate salt at body temperature invented by Chenite et al. (Chenite, Buschmann, Wang, Chaput \& Kandani, 2001), accompanied by genipin introduction as network reinforcement (Songkroh et al., 2015), and other synthetic or natural polymers (Sa-Lima, Caridade, Mano \& Reis, 2010).

The lack of appropriate stimuli to direct osteogenic differentiation of chitosan-based injectables often result in limited bone formation; therefore incorporation of bioceramic particles could overcome this drawback (Chen, Tsai \& Liao, 2013; Kim et al., 2007). Such improvement of biological stimulation of chitosan-based materials is a long-lasting field of interest and has lunched numerous investigations (Ji, Kuo, Wu, Yang \& Lee, 2012; Huang et al., 2011a, b; Moreira, Carvalho, Mansur \& Pereira, 2016; Baskar \& Kumar, 2011, Muzzarelli, 2011) indicating suitable microenvironment for osteogenic gene expression. The potential application of chitosan-hydroxyapatite based scaffolds, thermosensitive hydrogel and drug carriers as engineered tissues, has been proven by large number of in vitro and in vivo assays. The addition of hydroxyapatite phase into chitosan-based material has indicated better cell and protein adhesion, enhanced cell proliferation and higher osteogenic gene expression (Frohbergh et al., 2012; Peter et al., 2010). Moreover, stem cell culture on 
chitosan-hydroxyapatite scaffolds modified by growth factors has been proposed as good strategy for bone tissue reconstruction (Liu et al., 2013).

$\mathrm{pH}$ and thermosensitive chitosan-based injectables have been classified as slow in situ forming gels increasing the risk of biological toxicity to surrounding tissue and defined as low $\mathrm{pH}$ hydrated states compromising the viability of encapsulated cells (Couto, Hong \& Mano, 2009). In this study, we are proposing a new $\mathrm{pH}$-sensitive chitosan-based hydrogel providing neutral environment suitable for cell encapsulation. Our previous studies (Rogina, Rico, Gallego Ferrer, Ivanković \& Ivanković, 2016a; Rogina et al., 2016b) have proved noncytotoxic and osteogenic properties of chitosan-hydroxyapatite systems prepared as highly pre-formed porous scaffolds. Likewise, suitable hydroxyapatite fraction of $30 \%(w / w)$ has been indicated by stronger osteoinduction of mouse MC3T3-E1 preosteoblasts and human mesenchymal stem cells in longer culture. Therefore, we wanted to explore the ability of this chitosan-hydroxyapatite system as a hydrogel for cell delivery with minimal invasive surgery for bone tissue engineering. The in situ synthesis of calcium phosphate phase within chitosan matrix has resulted in $\mathrm{pH}$ higher than initial chitosan solution and subsequently ensured cell viability during encapsulation and hydrogel crosslinking. The application of sodium bicarbonate as a gelling agent has not produced any toxic by-products which may harm the viability of encapsulated cells. The physical crosslink was obtained as a result of glucosamine deprotonation with good resistance to applied shear deformation. The live dead staining indicated good cell distribution and viability during 7 days of culture. To the best of our knowledge, this is the first time that a chitosan-hydroxyapatite system with these characteristics is presented. Furthermore, the information of acidity of chitosan-based hydrogel as an important feature for cell surviving was stated, which similar investigations have not provided.

\section{Materials and methods}

\subsection{Materials}

Chitosan (Cht, $M_{\mathrm{w}}=100-300 \mathrm{~kg} / \mathrm{mol}$, deacetylation degree $=0.95-0.98$, Acros Organics), calcium carbonate $\left(\mathrm{CaCO}_{3}\right.$, calcite; TTT), urea phosphate $\left(\left(\mathrm{NH}_{2}\right)_{2} \mathrm{CO}-\mathrm{H}_{3} \mathrm{PO}_{4} ;\right.$ Aldrich Chemistry), acetic acid (HAc; POCH), sodium bicarbonate $\left(\mathrm{NaHCO}_{3}, \mathrm{Gram}-\mathrm{Mol}\right)$ were all of analytical grade and sterilized by UV light, autoclave or sterile filters $(0.22 \mu \mathrm{m})$.

\subsection{Synthesis of pH-responsive composite hydrogel}


The starting chitosan-hydroxyapatite suspension (Cht-HAp) was prepared with $30 \%(\mathrm{w} / \mathrm{w})$ of hydroxyapatite phase (HAp) by in situ precipitation reactions, based on our previous study (Rogina, Rico, Gallego Ferrer, Ivanković \& Ivanković, 2015): 1.2\% (w/w) of chitosan solution was prepared in $0.36 \%(w / w)$ acetic acid solution. In situ formation of hydroxyapatite was obtained by wet precipitation reaction from calcium and phosphate starting materials. To obtain final HAp weight ratio of $30 \%(w / w)$, specific amount of calcite as calcium source and appropriate amount of urea-phosphate as a phosphate source were added to chitosan solution, with respect to the hydroxyapatite $\mathrm{Ca} / \mathrm{P}$ ratio of 1.67 . Reaction was continued for 4 days at $50{ }^{\circ} \mathrm{C}$.

pH-responsive hydrogel was obtained using the sodium bicarbonate $\left(\mathrm{NaHCO}_{3}\right)$ as gelling and neutralization agent (figure 1) with concentration range of $0.040-0.067 \mathrm{mg} / \mathrm{L}$. Synthesized Cht-HAp suspension was cooled down to $10{ }^{\circ} \mathrm{C}$ by an ice bath and subsequently homogenized with $\mathrm{NaHCO}_{3}$ solution for $10 \mathrm{sec}$ by stirring at $1700 \mathrm{rpm}$. The gelation process of Cht-HAp suspension was then initiated by incubation at $37{ }^{\circ} \mathrm{C}$. Final physically crosslinked samples were designated as Gel-L, Gel-M and Gel-H for low $(0.040 \mathrm{mg} / \mathrm{L})$, medium $(0.053 \mathrm{mg} / \mathrm{L})$ and high $(0.067 \mathrm{mg} / \mathrm{L})$ concentration of $\mathrm{NaHCO}_{3}$, respectively. Additional modification of gelling agent solution was applied for the hydrogel with higher concentration of gelling agent: sodium bicarbonate was dissolved in basal $\alpha$-MEM (minimum essential medium) to obtain the concentration of $0.067 \mathrm{mg} / \mathrm{L}$ which was used for preparation of hydrogel, as previously described, designated as Gel-H-m. The composition of prepared crosslinked hydrogels is summarized in table 1 . The preparation of physically crosslinked chitosan-HAp hydrogel is illustrated in figure 1.

\subsection{Characterization of pH-responsive hydrogels}

The Fourier transform infrared spectra (FTIR) of crosslinked hydrogels dried at $40{ }^{\circ} \mathrm{C}$ were recorded by attenuated total reflectance (ATR) spectrometer for solids with a diamond crystal (Bruker Vertex 70) at $20{ }^{\circ} \mathrm{C}$ over the spectral range of $4000-400 \mathrm{~cm}^{-1}$, with 24 scans and 4 $\mathrm{cm}^{-1}$ of resolution.

Mineralogical composition of crosslinked hydrogels dried at $40{ }^{\circ} \mathrm{C}$ was investigated by X-ray diffraction analysis (XRD) using a Shimadzu XRD-6000 diffractometer with $\mathrm{Cu}$ Ka radiation operated at $40 \mathrm{kV}$ and $30 \mathrm{~mA}$, in the range of $5^{\circ}<2 \theta<70^{\circ}$ at a scan speed of $0.2^{\circ} \%$. 
Identification of crystal phases was done by ICDD (International Centre for Diffraction Data) card catalogue.

The $\mathrm{pH}$ of chitosan-HAp system was measured before and after gelation process on Schott CG $842 \mathrm{pH}$-meter using BlueLine 14 electrode with a precision of 0.01. Immediately after homogenizing the gelling agent at $10{ }^{\circ} \mathrm{C}$, the $\mathrm{pH}$ of chitosan- $\mathrm{HAp} / \mathrm{NaHCO}_{3}$ system was measured. The $\mathrm{pH}$ of physically crosslinked hydrogel was determined after $24 \mathrm{~h}$ of gel incubation at $37^{\circ} \mathrm{C}$.

The morphology of crosslinked hydrogels was imaged by the scanning electron microscope TESCAN Vega3SEM Easyprobe at electron beam energy of $10 \mathrm{keV}$. Prior to imaging, hydrogels were frozen at $-80{ }^{\circ} \mathrm{C}$, lyophilized and sputtered with gold and paladium for $120 \mathrm{~s}$.

\subsection{Rheological properties}

Rheological experiments were performed on a rheometer Discovery HR-2 Hybrid Rheometer (TA Instruments) at $37{ }^{\circ} \mathrm{C}$ with a Peltier plate and a solvent trap cover. The measurements were carried out on samples of $20 \mathrm{~mm}$ in diameter and with gap of $0.940 \mathrm{~mm}$ between the plane plates. To determine gelation time, time sweep oscillatory measurements at an angular frequency of $\omega=1.26 \mathrm{rad} / \mathrm{s}(0.2 \mathrm{~Hz})$ and $2 \%$ of strain were performed at $37{ }^{\circ} \mathrm{C}$.

Then, an amplitude test on physically crosslinked hydrogel was carried out at frequency of 0.2 $\mathrm{Hz}$ with a strain range from $0.01 \%$ to $100 \%$. The results indicated that a deformation of $2 \%$ is within the linear viscoelastic range, such that the storage modulus $\left(G^{\prime}\right)$ and loss modulus $\left(G^{\prime \prime}\right)$ were independent of the strain amplitude. Therefore, a constant strain (2\%) frequency sweep test was performed within frequency range of $0.1-800 \mathrm{rad} / \mathrm{s}$.

Rheological tests were performed on four replicas, while final curves were depicted as average values of individual measurements. The error bars were excluded from the final graphs for the sake clarity.

\subsection{Cytotoxicity evaluation}

To investigate the biocompatibility of physically crosslinked hydrogels, cytotoxicity evaluation was performed on mouse embryonic fibroblast cells. Fully crosslinked samples ( $n$ = 3) were incubated with basal $\alpha$-MEM medium at $37{ }^{\circ} \mathrm{C}$ for $24 \mathrm{~h}$. After incubation, the supernatant was collected, filtered through sterile filter $(0.22 \mu \mathrm{m})$ and used for cell feeding. 
Meanwhile, mouse embryonic fibroblast cells were thawed from liquid nitrogen and seeded into a $75 \mathrm{~cm}^{3}$ culture flask to achieve confluence. After 3 days cells were trypsinized with Tripsin/EDTA to obtain a cell suspension divided on $1.7 \times 10^{2}$ cells/well in 96-well plate, and incubated in humidified incubator with $5 \% \mathrm{CO}_{2}$ at $37{ }^{\circ} \mathrm{C}$. After $24 \mathrm{~h}$, cells were fed with supernatant from crosslinked samples and incubated for 24, 48 and 72 h. Basal $\alpha$-MEM medium was used as a negative control. Quantitative cell viability was determined by staining with (3-(4,5-dimethylthiazol-2-yl)-2,5-diphenyltetrazolium bromide) assay (MTT) at $570 \mathrm{~nm}$ using ThermoLabSystems MultiskanEX Microplate Reader.

\subsection{Viability and distribution of encapsulated cells}

Mouse fibroblasts were expanded in $75 \mathrm{~cm}^{3}$ flasks and incubated in a $5 \% \mathrm{CO}_{2}$ humidified atmosphere at $37{ }^{\circ} \mathrm{C}$ until confluence. $\alpha$-MEM medium supplemented with $10 \%$ fetal bovine serum (FBS) and 1\% penicillin/streptomycin was used as culture medium. After confluence, cells were harvested and encapsulated within the hydrogel at a density of $1 \times 10^{6}$ cells $/ 200 \mu \mathrm{L}$ of gelling Cht-HAp/ $\mathrm{NaHCO}_{3}$ suspension. The investigated hydrogel was synthesized under sterile conditions form chemicals previously sterilized by UV light for $15 \mathrm{~min}$ (chitosan), autoclave (calcite) or filtered through sterile filters (acetic acid solution, urea phosphate solution and $\mathrm{NaHCO}_{3}$ solution).

Prior to the cell encapsulation, $10 \mathrm{~mL}$ of synthesized Cht-HAp suspension was cooled down to $10{ }^{\circ} \mathrm{C}$ in an ice bath and kept at the same temperature and sterile conditions until cell encapsulation. Then, $1.5 \mathrm{~mL}$ of sterilized $\mathrm{NaHCO}_{3} / \alpha-\mathrm{MEM}$ solution with concentration of $0.067 \mathrm{mg} / \mathrm{L}$, previously cooled down at $10{ }^{\circ} \mathrm{C}$, was added as gelling agent. Immediately after homogenizing the Cht-HAp/ $\mathrm{NaHCO}_{3}$ system at $10{ }^{\circ} \mathrm{C}$ under sterile conditions, harvested cells were resuspended within. Cells resuspended in $\mathrm{Cht}-\mathrm{HAp} / \mathrm{NaHCO}_{3}$ system were quickly seeded onto 24 -well plate and incubated at $37{ }^{\circ} \mathrm{C}$ for $5 \mathrm{~min}$ to induce gelation. Afterwards, 2 $\mathrm{mL}$ of culture medium was added to each well and incubated for $1,2,3$ and 7 days. The culture medium was refreshed every three days.

Qualitative cell viability and distribution was evaluated by live dead assay using Live/Dead®Viability/Cytotxicity Kit (Invitrogen). Cultured samples were washed two times with sterile Dulbecco's phosphate buffer saline solution (DPBS) and incubated with $2 \mu \mathrm{mol} / \mathrm{L}$ calcein acetoxymethyl (calcein-AM) and $4 \mu \mathrm{mol} / \mathrm{L}$ ethidium homodimer (EthD-1) in humidified atmosphere with $5 \% \mathrm{CO}_{2}$ at $37{ }^{\circ} \mathrm{C}$ for $30 \mathrm{~min}$. Live cells (stained in green) and 
dead cells (stained in red) were analyzed by fluorescence microscope Axiovert $200 \mathrm{M}$, Zeiss, Göttingen, Germany with AxioVision software 4.5.

\subsection{Statistical analysis}

All experiments were performed in triplicate or more. Quantitative results are expressed as mean \pm standard deviation. Statistical analysis was performed using one-way ANOVA test to determine significant differences. A value of $p<0.05$ was considered statistically significant.

\section{Results}

\subsection{The composition identification and morphology of hydrogels}

The characterization of prepared systems was carried out by FTIR spectroscopy and XRD mineralogical analysis. Figure 2a represents FTIR spectra of starting suspension (Cht-HAp) and dried crosslinked hydrogels with different concentration of gelling agent (Gel-L, Gel-M, Gel-H and Gel-H-m).

Absorption bands characteristic for hydroxyapatite are clearly visible in all systems: absorption band at $1020-1014 \mathrm{~cm}^{-1}$ attributed to asymmetric stretching of phosphate band, band at $962 \mathrm{~cm}^{-1}$ associated to symmetric stretching of phosphates, bands at $599-595$ and $559-555 \mathrm{~cm}^{-1}$ attributed to asymmetric $\mathrm{PO}_{4}{ }^{3-}$ bending vibrations. Additionally, other calcium phosphate phases founded in Cht-HAp and crosslinked hydrogels with lower gelling agent concentration can be indicated by the weak absorption band at $525-520 \mathrm{~cm}^{-1}$ corresponding to $\mathrm{HPO}_{4}{ }^{2-}$ group, usually associated with dicalcium hydrogenphosphate dehydrate (DCPD) (Maity et al., 2011). On the other hand, Gel-H hydrogel shows absorption band at $875 \mathrm{~cm}^{-1}$ which could correspond to $\mathrm{CO}_{3}{ }^{2-}$ or $\mathrm{HPO}_{4}{ }^{2-}$ ion substitution in $\mathrm{HA}$ structure leading to formation of non-stoichiometric calcium-deficient HA (CDHA) or formation of additional calcium phosphate phase, OCP (octacalcium hydrogenphoshate pentahydrate). However, higher fraction of $\mathrm{NaHCO}_{3}$ as gelling agent leads to increase of carbonate ions within the hydrogel which could also result in $\mathrm{CO}_{3}{ }^{2-}$ specific absorption band (Lafon, Champion \& Bernache-Assollant, 2008).

Along with characteristic bands for calcium phosphate phases, typical chitosan groups are found at $1670-1660 \mathrm{~cm}^{-1}$ corresponding to amid I (carbonyl band of amid) and at 1567 $1552 \mathrm{~cm}^{-1}$ attributed to amid II (amino band of amid) (Pawlak \& Mucha, 2003). 
As expected, XRD analysis confirmed coexistence of several calcium phosphate phases in Cht-HAp suspension and crosslinked hydrogels. The diffraction pattern of Cht-HAp revealed coexistence of octacalcium phosphate and hydroxyapatite (OCP-HAp) which could be explained by formation of biphasic inorganic mixture or OCP-HAp interlayered crystals (figure $2 \mathrm{~b}$ ). The structural similarity of OCP and hydroxyapatite has been previously used for predictions of the epitaxial growth and formation of lamellar mixtures by these two minerals. The previous diffraction studies have confirmed diffraction patterns of independent crystals of OCP and HAp (Brown, Lehr, Smith \& Frazier, 1962). Likewise, the shift of (h00) position, depended on the $\mathrm{Ca} / \mathrm{P}$ ratio of interlayer, is occurring as a consequence of diffraction peak interaction (Brown, Schroeder \& Ferris, 1979). This maximum shift was detected for the plane (300) at $2 \theta=33.4^{\circ}$ of prepared systems with respect to the position of the same maximum at $2 \theta=32.9^{\circ}$ of hydroxyapatite standard (ICDD 9-432). Therefore, mixed structure of Cht-HAp consisting of apatitic lamellas sandwiching an OCP lamella is assumed. Slightly acidic nature of starting Cht-HAp suspension $(\mathrm{pH}=5.88$; table 2$)$ has provided precipitation of another calcium phosphate phase, dicalcium phosphate (DCPD), indicated by FTIR spectroscopy. However, the presence of very low diffraction intensity at $2 \theta=11.4^{\circ}$ points out very low concentration of DCPD in terms of few crystals within the inorganic mixture.

The mineralogical composition of crosslinked hydrogels has not been significantly changed after introducing the $\mathrm{NaHCO}_{3}$ as gelling agent, although, structural changes of crystalline phase were noted by the alteration of diffraction maxima shape (figure $2 b$ ). The basic structure proposed for OCP phase is a layered structure composed of apatitic and hydrate lamellas in which water molecules are loosely bonded and being able to enter or leave OCP lattice. Nonetheless, this region is capable to transport calcium or other ions that can be incorporated into resulting apatitic product during transformation or hydrolysis of OCP (Mathew \& Takagi, 2001). The gelation mechanism of crosslinked hydrogels is based on hydrolysis of $\mathrm{NaHCO}_{3}$ in slightly acid environment releasing the sodium and carbonate ions which can be substituted within apatite lattice. Such cationic and anionic substitution can result with dimensional changes of crystal lattice in terms of $a$ - or $c$-axis decrease. Moreover, the $\mathrm{pH}$ values of fully crosslinked hydrogels at $37{ }^{\circ} \mathrm{C}$ (table 2) do not show significant difference by changing the concentration of $\mathrm{NaHCO}_{3}$, which provided similar environment for thermodynamically depended calcium phosphate phases. 
Beside the possibility of $\mathrm{Na}^{+}$and $\mathrm{CO}_{3}{ }^{2-}\left(\mathrm{HCO}_{3}{ }^{-}\right)$incorporation into apatitic layer, the formation of sodium carbonate $\left(\mathrm{Na}_{2} \mathrm{CO}_{3}\right)$ and sodium acetate $\left(\mathrm{CH}_{3} \mathrm{COONa}\right)$ as products of hydrogel gelation process is assumed. However, the lack of its identification as a crystalline phase in figure 3 can be explained by the possible formation of amorphous domains nondetectable by the X-ray diffraction.

The $\mathrm{pH}$ measurement of physically crosslinked hydrogels confirmed physiological environment at $37{ }^{\circ} \mathrm{C}$ which could allow encapsulation of cells without affecting their viability. Likewise, theoretical concentrations of sodium ions calculated from the final composition of physically crosslinked hydrogels are in the range of $61.9-103.5 \mathrm{mmol} / \mathrm{L}$ which is below the reference values of sodium in interstitial fluid and plasma (125 - 135 $\mathrm{mmol} / \mathrm{L}$ ) (Schrier, 2010). Thus, injection of such hydrogel into damaged tissue site would not impair the homeostasis.

The increase of gelling agent concentration has impacted on hydrogels' initial $\mathrm{pH}$ values measured at the moment of homogenizing Cht-HAp/ $/ \mathrm{NaHCO}_{3}$ system, however, significant difference in $\mathrm{pH}$ of fully crosslinked systems did not occurred. Sodium bicarbonate is known for its application as a buffering agent in essential tissue culture medium with $\mathrm{pH}$ values 7.3 7.5. This corresponds to the effect of maintaining the $\mathrm{pH}$ value of crosslinked hydrogels with different concentration of gelling agent without any disintegrations of the hydrogel or phase separation.

Preliminary trials of gelation time (data not shown) have pointed out the faster gelation time with higher $\mathrm{NaHCO}_{3}$ concentration. Considering the application of cellular hydrogels, we have focused on the hydrogel system with the highest gelling agent concentration. Also, to provide essential nutrients during the cell encapsulation, gelling agent solution was modified by $\alpha$-MEM medium (Gel-H-m hydrogel). Such modification has resulted in uniform composition of Gel-H-m hydrogel with hydroxyapatite as only inorganic phase, confirmed by diffraction maxima at $2 \theta=26^{\circ}$ and $32^{\circ}$ (figure $2 \mathrm{~b}$ ). Higher $\mathrm{pH}$ value of crosslinked Gel-H-m hydrogel $(\mathrm{pH}=7.70)$ has provided complete transformation of primary formed calcium phosphate phases (OCP and DCPD) into hydroxyapatite. Additionally, highly porous structure is characteristic for lyophilized Gel-H-m hydrogel (figure 3) which is essential parameter for oxygen, nutrients and metabolic waste diffusion. The characteristic cauliflower morphology consisted of nanometric plate-like hydroxyapatite crystals homogeneously distributed can be observed. 


\subsection{Rheological behaviour of pH-responsive hydrogel}

The correlation of storage $\left(G^{\prime}\right)$ and loss modulus $\left(G^{\prime \prime}\right)$ of Gel-H-m hydrogel with shear parameters is depicted in figure 4.

As seen from figure $4 \mathrm{a}$, the rapid modulus increase is observed within 4 min from adding the gelling agent, after which $G^{\prime}$ is slightly rising. The crosslinking nature of prepared hydrogel reveals gelation in a percolating manner that brings another influencing parameter on kinetics of gelation, which is the geometry of initial solution. The hydration of chitosan should be favoured in acetate form in which formation of a complex between glucosamine groups and acetate anion is highlighted (Boucard, Viton \& Domard, 2005). It is assuming that lower solubility and acidity of acetic acid and its salt, along with complex stability could be a reason for fast gelation of chitosan-based hydrogel. At low $\mathrm{pH}$, chitosan chains become polycationic owing protonated amine groups $\left(-\mathrm{NH}_{3}{ }^{+}\right)$which cause electrostatic repulsion between the chains. This repulsion also depends on deacetylation degree which is influencing parameter of chitosan gelation. However, this repulsion is partially screened by the hydroxyapatite particles. The presence of sodium bicarbonate is responsible for $\mathrm{pH}$ increase due to formation of mild base salt $\left[\mathrm{Cht}-\mathrm{NH}_{3}{ }^{+}\right]\left[\mathrm{HCO}_{3}{ }^{-}\right]$, and carbon dioxide production that would lead to chitosan deprotonization. At this point, charge repulsion is reducing while intra- and interchain interactions contribute to the reinforcement of chitosan network. Finally, chain entanglements were developed by generated hydrogen bonding between deprotonated $-\mathrm{NH}_{2}$ and $-\mathrm{OH}$ groups; and interactions of of $\mathrm{N}$-acetyl groups and main polysaccharide backbone (Chiu et al., 2009; Rinaudo, 2006; Osada \& Kajiwara, 2001).

Evaluation of storage modulus of Gel-H-m hydrogel as a function of time has implied the effect of hydroxyapatite particles on shear strength of composite hydrogel. At 1200 seconds of time sweep measurement, storage modulus of the gel is around $100 \mathrm{~Pa}$. Similarly, storage modulus of chitosan $/ \mathrm{NaHCO}_{3}$ system with $\mathrm{NaHCO}_{3}$ concentration of $0.08 \mathrm{~mol} / \mathrm{L}$, prepared by Liu et al. (Liu, Tang, Wang \& Guo, 2011), shows comparable value at the same test point. It is important to emphasize that $\mathrm{NaHCO}_{3}$ concentration in Gel-H-m hydrogel is almost eight times lower $(0.013 \mathrm{~mol} / \mathrm{L})$ than in chitosan/ $\mathrm{NaHCO}_{3}$ hydrogel prepared by Liu et al., which indicates positive influence of hydroxyapatite on storage modulus of Gel-H-m gel.

The intersection of elastic and viscous modulus has been widely accepted to determine the gel point. However, such strategy cannot be applied for presented hydrogel since intersection is 
appearing at very beginning of rheological measurement. The cross section where interpolations of initial and ending region of $G^{\prime}-t$ curve meet (Poveda-Reyes et al., 2016) is defined as gelation time of $\sim 260 \mathrm{sec}$ (figure $4 \mathrm{~b}$ ), while rheological parameters of physically crosslinked hydrogel are evaluated at frequency of $0.2 \mathrm{~Hz}$ and $2 \%$ of strain at $37{ }^{\circ} \mathrm{C}: G^{\prime}=$ $102.20 \pm 9.02 \mathrm{~Pa} ; G^{\prime \prime}=4.33 \pm 0.37 \mathrm{~Pa}$ and loss factor $(\tan \delta)=0.042 \pm 0.04$.

The large difference between $G^{\prime}$ and $G^{\prime \prime}$ (figure 4c) confirms elastic behaviour of investigated hydrogel. Moreover, the wide storage modulus plateau in frequency range (figure 4d) with ratio $G^{\prime} / G^{\prime \prime}>1$ defines Gel-H-m as a 'true gel' (Picout \& Ross-Murphy, 2003; NilsenNygaard, Strand, Varum, Draget \& Nordgard, 2016).

\subsection{Biological evaluation of pH-responsive hydrogel}

\subsubsection{Cytotoxicity test}

One of the simplest biological characterization of potential tissue regeneration materials is cytotoxicity evaluation. The MTT test was performed on mouse embryonic fibroblasts cultured with Gel-H-m supernatant up to 3 days. Similar absorbance of investigated hydrogel and negative control ( $\alpha$-MEM without previous contact with material) indicates no harmful effect and good biocompatibility of Gel-H-m hydrogel (figure 5).

\subsubsection{Live dead assay of encapsulated cells}

The live dead assay of cells encapsulated within Gel-H-m hydrogel (figure 6) points out good cell viability which increases with the culture time. The fibroblast cells are homogeneously dispersed without forming the agglomerates. The predominant factor for injectable cell carriers is the quantity of dead cells or cells being in apoptosis. It is important to emphasize that number of dead cells determined by the fluorescence micrographs remained practically the same during whole culture experiment which indicates suitable environment for cell growth and proliferation. Quantification analysis performed by counting live and dead cells has confirmed good cell viability determined as a percentage of live cells with respect to the total cells counted in both channels. The cell viability has increased by the culture time, with good initial trend from $76.4 \%$ at day $1,80.3 \%$ at day 2 , to $87.9 \%$ at day 3 , and stagnation at day 7 with $83.0 \%$ of live cells. 
The cell homogeneity through the crosslinked Gel-H-m hydrogel can imply the absence of chemical or physical barrier After 7 days of culture; small defects in terms of small cracks were noticed on the surface of the hydrogels.

\section{Discussion}

In situ synthesis of hydroxyapatite is a hydrothermal precipitation reaction based on transformation mechanisms of primary formed calcium phosphate species. The slightly acid conditions of prepared starting Cht-HAp suspension with $\mathrm{pH}$ value of $\sim 5.9$ have affected the kinetics and mineralogical composition of the final inorganic phase. Since dicalcium phosphate (DCPD) and octacalcium phosphate (OCP) are thermodynamically stable at $\mathrm{pH} 2$ 6.5 and $5.5-7$, respectively, their coexistence with hydroxyapatite is expected (Dorozhkin, 2009). Hydroxyapatite is known to be stable calcium phosphate phase at physiological conditions. However, the stability decreases with nonstoichiometry ( $\mathrm{CaP} \neq 1.67$ ) caused by the presence of impurities within the lattice, such as carbonate ions, which are responsible for better materials bioresorption in physiological conditions (Suzuki, 2013). This can lead to decrement in crystal size, which usually increases materials dissolution, and induces physicochemical changes and possible formation of another phase. Calcium phosphatehydroxyapatite system (DCPD-OCP-HA) is confirmed in crosslinked hydrogels Gel-L, Gel-M and Gel-H. Former evidences have confirmed osteoconductivity of OCP with ability to enhance bone regeneration in bone defect of various animal models. Moreover, implantation of OCP-material into bone tissue may emulate the onset of bone formation by osteoblasts in terms of morphological features of initial bone deposition (Ban, Jinde \& Hasegawa, 1992). Previous X-ray diffraction analysis confirmed that implanted OCP tends to gradually convert to apatite in various bone sites or subcutaneous tissue. Even though the $\mathrm{pH}$ values of physically crosslinked hydrogels are beyond thermodynamically stable environment for dicalcium phosphate (DCPD), its existence was found in trace. However, thermodynamically metastable calcium phosphates are avoided by the modification of gelling agent solution, which was confirmed by hydroxyapatite as only mineralogical phase in Gel-H-m crosslinked system.

Several possible interactions have been proposed to explain the gelation behaviour of chitosan based systems, which might also be suitable for the investigated system. As illustrated in Figure 1 prior to addition of sodium bicarbonate $\left(\mathrm{NaHCO}_{3}\right)$ as the gelling agent, in situ synthesized HAp-chitosan suspension need to be cooled down. Sodium bicarbonate is known as a weak base. Slightly acid environment of chitosan-HAp system favours dissociation of 
sodium bicarbonate that releases hydrogen carbonate ions $\left(\mathrm{HCO}_{3}{ }^{-}\right)$responsible for carbon dioxide production and $\mathrm{pH}$ increase. An equilibrium between protonated $\left(\mathrm{Cht}-\mathrm{NH}_{3}{ }^{+}\right)$and deprotonated $\left(\mathrm{Cht}-\mathrm{NH}_{2}\right)$ chitosan unit is also responsible for generation of $\mathrm{CO}_{2}$, as proposed by Liu et al. (Liu, Tang, Wang \& Guo, 2011). Such neutralization reaction would reach different balance depending on the temperature and the release of $\mathrm{CO}_{2}$, which controls the sol-gel transition. Although the sol-gel transitions in chitosan/ $\mathrm{NaHCO}_{3}$ appeared to be thermally-sensitive upon the temperature increase, these systems performed actually the $\mathrm{pH}$ induced gelation process. The decrease of the apparent charge density of chitosan chains reduces the electrostatic repulsion between chitosan molecules allowing the formation of the three-dimensional chitosan network due to physical junctions of hydrogen bonds. The physical crosslinking based on neutralization is irreversible at physiological $\mathrm{pH}$ and low temperature; however, acidic environment will cause protonation of amine groups and reverse reaction.

Physically crosslinked hydrogels based on neutralization mechanism cannot exhibit high shear strength as chemically crosslinked chitosan hydrogels. According to Borzacchiello and Ambrosio (Borzacchiello \& Ambrosio, 2007), chemical and physical gels can be distinguished by their mechanical spectra. Typical spectrum of chemically crosslinked gel is characterized by almost horizontal straight line were $G^{\prime}$ and $G^{\prime \prime}$ curves are frequency independent and parallel; and fulfil the $G^{\prime \prime} / G^{\prime}$ ratio lower than 0.1 . On the other hand, they classify the gel with $G^{\prime \prime} / G^{\prime}$ ratio higher than 0.1 as a physical (weak) gel, such as proteins and polysaccharide networks. Additionally, physically crosslinked hydrogels can be subdivided into strong with permanent physical bond at given conditions; and weak gels with reversible links formed form temporary associations between chains (Gulrez, Al-Assaf \& Phillips, 2011). Likewise, strong physical gels behave as viscoelastic solids at both small and large deformations with strains up to $25 \%$, while weak physical gels respond at deformation strains up to 5\% (Co \& Marangoni, 2012). The viscoelastic behaviour of Gel-H-m hydrogel was observed in the range of strain deformation up to approximately $10 \%$, after which storage modulus started to slightly increase (figure $4 \mathrm{~b}$ ). Considering $G^{\prime \prime} / G^{\prime}$ ratio of 0.042 and linear viscoelasticity above $5 \%$ of strain deformation, Gel-H-m hydrogel could behave as strong physical gel.

Based on previously reported physical hydrogels, our Gel-H-m crosslinked hydrogel possesses 1.5-fold higher storage modulus with respect to the storage modulus of similar physically crosslinked chitosan-based system with $30 \%(w / w)$ of bioglass nanoparticles and $\beta$ glycerophosphate as a gelling agent prepared by Couto et al. (Couto, Hong \& Mano, 2009). 
One of the important features of cellular hydrogels is their acidity which influences the cellular behaviour during encapsulation and first stages of cell viability before the implantation. The $\mathrm{pH}$ of biological medium would be favourable physiological environment for encapsulated cells; although pH range of 6.8 - 8 (Hinderling \& Hartmann, 2005) (6.9 7.8 (Ceccarini \& Eagle, 1971)) is determined to be acceptable for cell surviving and viability. Even at lower concentration of gelling agent, and with modification of gelling agent solution, prepared crosslinked hydrogels could provide environment suitable for cell surviving

Looking at the potential application as a cell carrier and delivery, prepared hydrogel has to maintain cell viability during their suspension and hydrogel crosslinking process. Chitosan-based hydrogel are know for their low $\mathrm{pH}$ value during hydrated state which can compomise cell viability before delivering them to the damage site (Chenite et al., 2002). However, in situ synthesis of hydroxyapatite phase has resulted in higher $\mathrm{pH}$ value of starting suspension, which has facilitated the preparation of hydrogel without applying excessive amount of gelling agent. Comparing the high cell death of rBMSCs encapsulated within chitosan-hydroxyapatite/ $\mathrm{Na}_{2} \mathrm{CO}_{3}$ injectable hydrogel recently prepared by $\mathrm{Li}$ et al. (Li, Liu, Ding \& Xie, 2014), we have successfully maintained the cell viability during encapsulation and culture by combining the chitosan-hydroxyapatite system with $\mathrm{NaHCO}_{3} / \alpha-\mathrm{MEM}$ as the gelling agent.

Bearing in mind good biocompatibility, presented Cht- $\mathrm{HAp} / \mathrm{NaHCO}_{3}$ system might show potential as a cell carrier for bone tissue engineering. The synthesis of such system does not involve complex and potentially cytotoxic crosslinking reactions which could disminish the viability of encapsulated cells. The buffering ability of sodium bicarbonate as gelling agent was benefit to obtain mild and neutral crosslinked hydrogel suitable for cell surviving. Furthermore, in situ precipitation of hydroxyapatite provides lower acidity of chitosan solution which facilitates the preparation of physically crosslinked hydrogel with reduced concentration of gelling agent.

\section{Conclusions}

This work presents novel chitosan-hydroxyapatite hydrogel physically crosslinked with sodium bicarbonate. The in situ synthesis of apatite phase has facilitated the physical crosslinking reaction by reducing the acidity of chitosan solution. Consequently, significantly lower amount of sodium bicarbonate was required to obtain fast gelation of chitosanhydroxyapatite hydrogel with respect to the previously reported similar studies. Positive cell encapsulation indicates possible application of prepared hydrogel as a cell carrier. However, 
further studies involving biodegradability assay using animal model, and encapsulation of stem or preosteoblastic lineage needs to be performed in order to confirm the usage of these hydrogels as bone tissue engineering materials.

\section{Acknowledgements}

This work has been supported in part by the Croatian Science Foundation under the project IP-2014-09-3752. The authors want to thank Carlos Garcia Fernández from TA Instruments for helping with rheological measurements. G. Gallego Ferrer is grateful for the financial support of the Spanish Ministry of Economy and Competitiveness through the MAT201676039-C4-1-R project (including Feder funds).

\section{References}

Amini, A. A., Nair, L. S. (2012). Injectable hydrogels for bone and cartilage repair. Biomedical Materials, 7, 24105 - 24118.

Ban, S., Jinde, T., Hasegawa, J. (1992). Phase transformation of octacalcium phosphate in vivo and in vitro. Dental Materials Journal, 11, 130 - 140.

Baskar, D., Balu, R., Kumar, T. S. S. (2011). Mineralization of pristine chitosan film through biomimetic process. International Journal of Biological Macromolecules, 49, 385 - 389.

Bi, L., Cheng, W., Fan, H., Pei, G. (2010). Reconstruction of goat tibial defects using an injectable tricalcium phosphate/chitosan in combination with autologous platelet-rich plasma. Biomaterials, 31, 3201 - 3211 .

Borzacchiello, A., Ambrosio, L. (2007). Structure-property relationships in hydrogels, in Hydrogels: biological properties and applications, ed. R. Barbucci, Springer-Verlag, Milan, Italy.

Boucard, N., Viton, C., Domard, A. (2005). New aspects of the formation of physical hydrogels of chitosan in a hydroalcoholic medium. Biomacromolecules, 6, $3227-3237$.

Brown, W. E., Lehr, J. R., Smith, J. P., Frazier, A. W. (1962). Crystallographic and chemical relations between octacalcium phosphate and hydroxyapatite. Nature, 196, 1050 - 1055.

Brown, W. E., Schroeder, L. W., Ferris, J. S. (1979). Interlayering of crystalline octacalcium phosphate and hydroxyapatite. Journal of Physical Chemistry, 83, 1385 - 1388.

Cao, L., Cao, B., Lu, C., Wang, G., Yu, L., Ding, J. (2015). An injectable hydrogel formed by in situ cross-linking of glycol chitosan and multi-benzaldehyde functionalized PEG analogues for cartilage tissue engineering. Journal of Materials Chemistry B, 3, $1268-1280$.

Ceccarini, C., Eagle, H. (1971). pH as a determinant of cellular growth and contact inhibition, PNAS, Proceedings of the National Academy of Sciences, 68(1), 229 - 233. 
Chen, J.-P., Tsai, M.-J., Liao, H.-T. (2013). Incorporation of biphasic calcium phosphate microparticles in injectable thermoresponsive hydrogel modulates bone cell proliferation and differentiation. Colloids and Surface B: Biointerfaces, 110, 120 - 129.

Chenite, A., Buschmann, M., Wang, D., Chaput, C., Kandani, N. (2001). Rheological characterisation of thermogelling chitosan/glycerol-phosphate solutions. Carbohydrate Polymers, 46, 39 - 47.

Chenite, A., Chaput, C., Wang, D., Combes, C., Buschmann, M. D., Hoemann, C. D., Leroux, J. C., Atkinson, B. L., Binette, F., Selmani, A. (2002). Novel injectable neutral solutions of chitosan form biodegradable gels in situ. Biomaterials, 21, 2155 - 2161.

Chiu, Y.-L., Chen, S.-C., Su, C.-J., Hsiao, C.-W., Chen, Y.-M., Chen, H.-L., Sung, H.-W. (2009). pH-triggered injectable hydrogels prepared from aqueous N-palmitoyl chitosan: In vitro characteristics and in vivo biocompatibility. Biomaterials, 30, $4877-4888$.

Co, E., Marangoni, A. G. (2012). Structured organogels based on vegetable oils and surfactants-structures, characterization and applications, in: Nanotechnologies for solubilisation and delivery in foods and cosmetics pharmaceuticals, eds: N. Garti and I. AmarYuli), DEStech Publications, Inc. Lancaster, USA.

Couto, D. S., Hong, Z., Mano, J. F. (2009). Development of bioactive and biodegradable chitosan-based injectable systems containing bioactive glass nanoparticles. Acta Biomaterialia, 5, 115 - 123.

Dorozhkin, S. V. (2009). Nanodimensional and nanocrystalline apatites and other calcium orthophosphates in biomedical engineering, biology and medicine. Materials, 2, 1975 - 2045.

Frohbergh, M.E., Katsman, A., Botta, G.P., Lazarovici, P., Schauer, C.L., Wegst, U.G.K., Lelkes, P.I. (2012). Electrospun hydroxyapatite-containing chitosan nanofibers crosslinked with genipin for bone tissue engineering. Biomaterials, 33, $9167-9178$.

Gulrez, S. K. H., Al-Assaf, S., Phillips, G. O. (2011) Hydrogels: methods of preparation, characterisation and applications, in: Progress in molecular and environmental bioengineering - from analysis and modeling to technology applications, ed. A. Carpi, InTech, DOI: $10.5772 / 24553$.

Hinderling, P. H., Hartmann, D. (2005). The pH dependency of the binding of drugs to plasma proteins in man. Therapeutic Drug Monitoring, 27, 71 - 85.

Huang, Z., Feng, Q., Yu, B., Li, S. (2011). Biomimetic properties of an injectable chitosan/nano-hydroxyapatite/collagen composite. Materials Science and Engineering C, 31, $683-687$.

Huang, Z., Yu, B., Feng, Q., Li, S., Chen, Y., Luo, L. (2011). In situ-forming chitosan/nanohydroxyapatite/collagen gel for the delivery of bone marrow mesenchymal stem cells. Carbohydrate Polymers, 85, 261 - 267.

Ji, D.-Y., Kuo, T.-F., Wu, H.-D., Yang, J.-C., Lee, S.-Y. (2012). A novel injectable chitosan/polyglutamate polyelectrolyte complex hydrogel with hydroxyapatite for soft-tissue augmentation. Carbohydrate Polymers, 89, 1123 - 1130. 
Kim, S.-S., Ahn, K. M., Park, M. S., Lee, J.-H., Choi, C. Y., Kim, B.-S. (2007). A poly(lactide coglycolide)/hydroxyapatite composite scaffold with enhanced osteoconductivity. Journal of Biomedical Materials Research Part A, 80, 206 - 215

Kumar, D., Gerges, I., Tamplenizza, M., Lenardi, C., Forsyth, N. R., Liu, Y. (2014). Threedimensional hypoxic culture of human mesenchymal stem cells encapsulated in a photocurable, biodegradable polymer hydrogel: A potential injectable cellular product for nucleus pulposus regeneration. Acta Biomaterialia, 10, 3463 - 3474.

Lafon, J. P., Champion, E., Bernache-Assollant, D. (2008). Processing of AB-type carbonated hydroxyapatite $\mathrm{Ca}_{10-\mathrm{x}}\left(\mathrm{PO}_{4}\right)_{(6-\mathrm{x})}\left(\mathrm{CO}_{3}\right)_{(\mathrm{x})}(\mathrm{OH})_{(2-\mathrm{x}-2 \mathrm{y})}\left(\mathrm{CO}_{3}\right)_{(\mathrm{y})}$ ceramics with controlled composition. Journal of European Ceramic Society, 28, 139 - 147.

Li, H., Ji, Q., Sun, Y., Xu, Q., Song, W., Li, W., Li, D., Deng, P., Hu, F., Yang, J. (2016). Accelerated bony defect healing based on chitosan thermosensitive hydrogel scaffolds embedded with chitosan nanoparticles for the delivery of BMP2 plasmid DNA. Journal of Biomedical Materials Research Part A, in press, doi: 10.1002/jbm.a.35900.

Li, F., Liu, Y., Ding, Y., Xie, Q. (2014). A new injectable in situ forming hydroxyapatite and thermosensitive chitosan gel promoted by $\mathrm{Na}_{2} \mathrm{CO}_{3}$. Soft Matter, 10, $2292-2303$.

Liu, H., Peng, H., Wu, Y., Zhang, C., Cai, Y., Xu, G., Li, Q., Chen, X., Ji, J., Zhang, Y. (2013). The promotion of bone regeneration by nanofibrous hydroxyapatite/chitosan scaffolds by effects on integrin-BMP/Smad signaling pathway in BMSCs, Biomaterials, 34, 4404 4417.

Liu, L., Tang, X. M., Wang, Y. Y., Guo, S. R. (2011). Smart gelation of chitosan solution in the presence of $\mathrm{NaHCO}_{3}$ for injectable drug delivery system, International Journal of Pharmaceutics, 414 (1-2), 6 - 15.

Maity, J. P., Lin, T.-J., Cheng, H. P.-H., Chen, C.-Y., Reddy, A. S., Atla, S. B., Chang, Y.-F., Chen, H.-R., Chen, C.-C. (2011). Synthesis of brushite particles in reverse microemulsions of the biosurfactant surfactin. International Journal of Molecular Sciences, 12, 3821 - 3830.

Mathew, M., Takagi, S. (2001). Structures of biological minerals in dental research. Journal of Research of the National Institute of Standards and Technology, 106, 1035 - 1044.

Moreira, C. D., Carvalho, S. M., Mansur, H. S., Pereira, M. M. (2016). Thermogelling chitosan-collagen-bioactive glass nanoparticle hybrids as potential injectable systems for tissue engineering. Materials Science and Engineering C, 58, 1207 - 1216.

Muzzarelli, R. A. A. (2011). Chitosan composites with inorganic, morphogenetic proteins and stem cells, for bone regeneration. Carbohydrate Polymers, 83, 1433 - 1445.

Nilsen-Nygaard, J., Strand, S. P., Varum, K. M., Draget, K. I., Nordgard, C. T. (2016). Chitosan: gels and interfacial properties. Polymers, 7, $552-579$.

Osada, Y., \& Kajiwara, K. (2001). Gels Handbook 1: The fundamentals. (1 ${ }^{\text {st }}$ ed.) New York: Academic Press.

Pawlak, A., Mucha, M. (2003). Thermogravimetric and FTIR studies of chitosan blends. Thermochimica Acta, 396, 153 - 166. 
Peter, M., Ganesh, N., Selvamurugan, N., Nair, S.V., Furuike, T., Tamura, H., Jayakumar, R. (2010). Preparation and characterization of chitosan-gelatin/nanohydroxyapatite composite scaffolds for tissue engineering applications, Carbohydrate Polymers, 80, 687 - 694.

Picout, D. R., Ross-Murphy, S. B. (2003). Rheology of biopolymer solution and gels. Scientific World Journal, 3, 105 - 121.

Poveda-Reyes, S., Moulisova, V., Sanmartín-Masiá, E., Quintanilla-Sierra, L., SalmerónSánchez, M., Gallego Ferrer, G. (2016). Gelatin-hyaluronic acid hydrogels with tuned stiffness to counterbalance cellular forces and promote cell differentiation. Macromolecular Bioscience, 16, 1311 - 1324.

Rinaudo, M. (2006). Non-Covalent Interactions in Polysaccharide Systems. Macromolecular Bioscience, 6, $590-610$.

Rogina, A., Rico, P., Gallego Ferrer, G., Ivanković, M., Ivanković, H. (2015). Effect of in situ formed hydroxyapatite on microstructure of freeze-gelled chitosan-based biocomposite scaffolds. European Polymer Journal, 68, 278 - 287.

Rogina, A., Rico, P., Gallego Ferrer, G., Ivanković, M., Ivanković, H. (2016). In situ hydroxyapatite content affects the cell differentiation on porous chitosan/hydroxyapatite scaffolds. Annals of Biomedical Engineering, 44, 1107 - 1119.

Rogina, A., Pribolšan, L., Hanžek, A., Gómez-Estrada, L., Gallego Ferrer, G., Marijanović, I., Ivanković, M., Ivanković, H. (2016). Macroporous poly(lactic acid) construct supporting the osteoinductive porous chitosan-based hydrogel for bone tissue engineering. Polymer, 98, 172 -181 .

Sa-Lima, H., Caridade, S. G., Mano, J. F., Reis, R. L. (2010). Stimuli-responsive chitosanstarch injectable hydrogels combined with encapsulated adipose-derived stromal cells for articular cartilage regeneration. Soft Matter, 6, 5184 - 5195.

Schrier, R. W. (2010). Does 'asymptomatic hyponatremia' exist? Nature Reviews Nephrology, 6, 185.

Songkroh, T., Xie, H., Yu, W., Liu, X., Sun, G., Xu, X., Ma, X. (2015). Injectable in situ forming chitosan-based hydrogels for curcumin delivery. Macromolecular Research, 23, 53 59 .

Suzuki, O. (2013). Octacalcium phosphate (OCP)-based bone substitute materials. Japanese Dental Science Review, 49, 58 - 71.

Ta, H. T., Dass, C. R., Dunstan, D. E. (2008). Injectable chitosan hydrogels for localised cancer therapy. Journal of Control Release, 126, 205 - 216.

Tan, H., Marra, K. G. (2010). Injectable, biodegradable hydrogels for tissue engineering applications. Materials, 3, $1746-1767$.

Yan, J., Yang, L., Wang, G., Xiao, Y., Zhang, B., Qi, N. (2010). Biocompatibility evaluation of chitosan-based injectable hydrogels for the culturing mice mesenchymal stem cells in vitro. Journal of Biomaterials Application, 24, 625 - 637. 
Yasmeen, S., Lo, M. K., Bajracharya, S., Roldo, M. (2014). Injectable scaffolds for bone regeneration. Langmuir, 30, 12977 - 12985. 

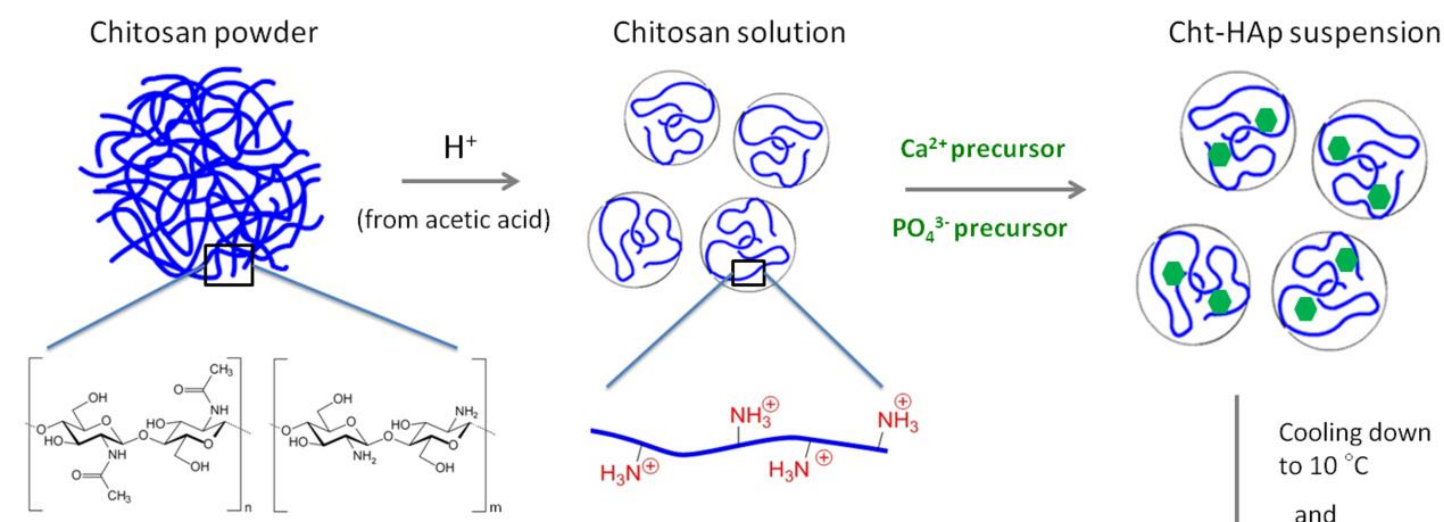

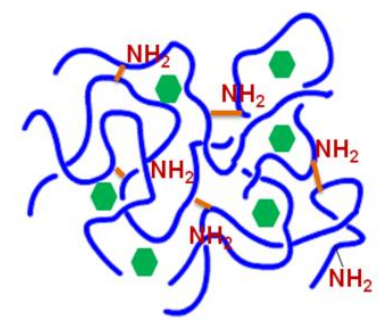

Physically crosslinked Cht-HAp hydrogel

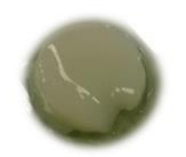

Incubation at $37^{\circ} \mathrm{C}$

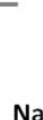

$\mathrm{NaHCO}_{3} \rightleftarrows \mathrm{Na}^{+}+\mathrm{HCO}_{3}$

$\mathrm{H}^{+}+\mathrm{HCO}_{3} \cdot \mathrm{H}_{2} \mathrm{CO}_{3} \rightleftarrows \mathrm{CO}_{2}^{\uparrow}+\mathrm{H}_{2} \mathrm{O}$

Cht- $\mathrm{NH}_{3}{ }^{+}+\mathrm{HCO}_{3} \rightleftarrows \mathrm{Cht}-\mathrm{NH}_{2}+\mathrm{CO}_{2}{ }^{\uparrow}+\mathrm{H}_{2} \mathrm{O}$

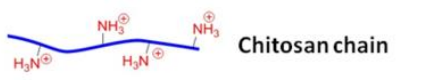

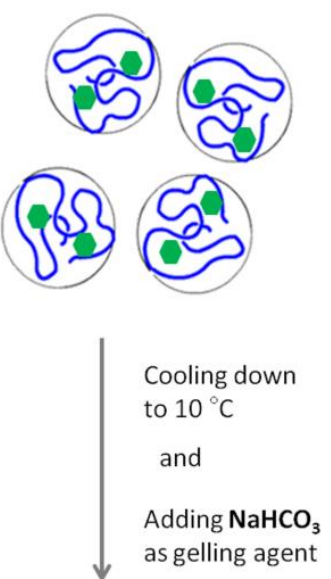

as gelling agent

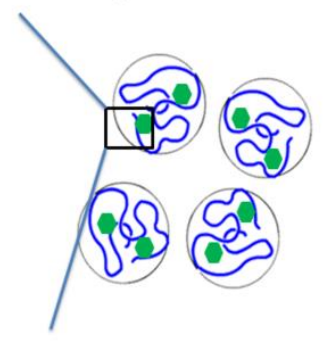

HAp particle - Chain interaction

Figure 1. Preparation of physically crosslinked chitosan-HAp hydrogel. For a detailed explanation see the Discussion section. 
a)

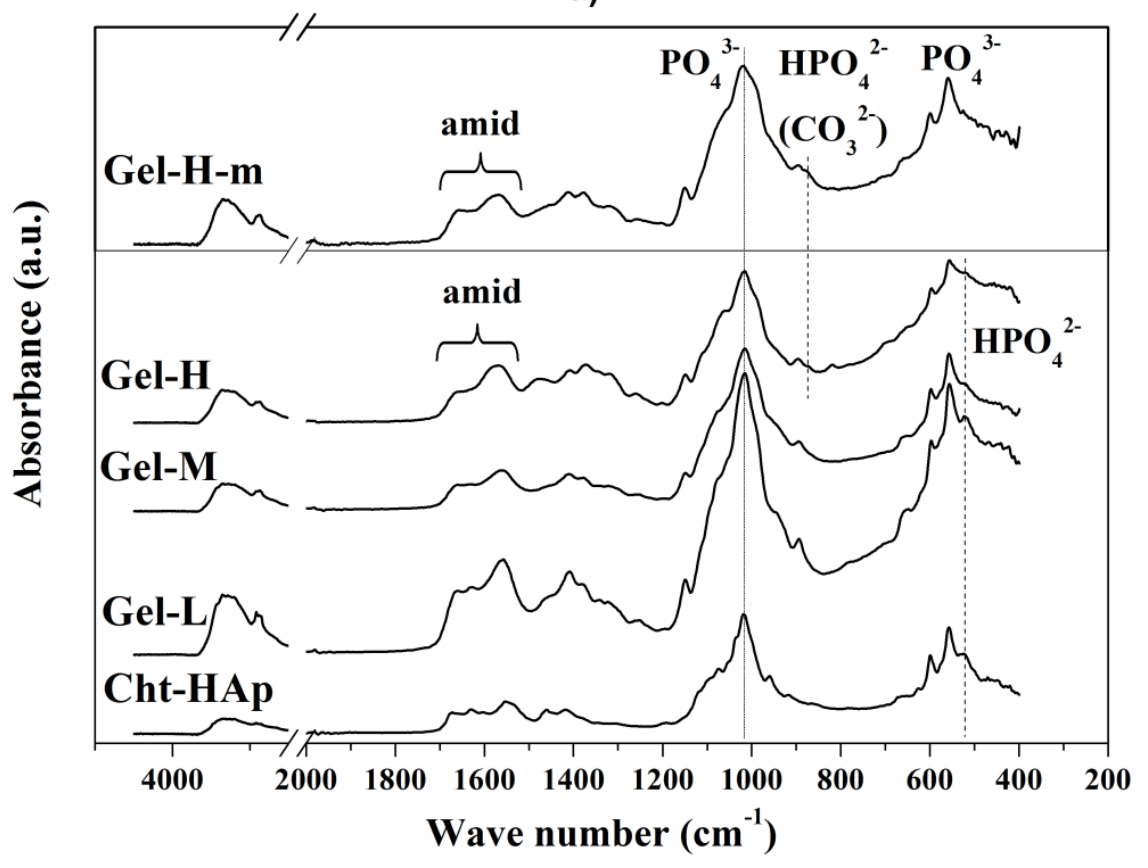

b)

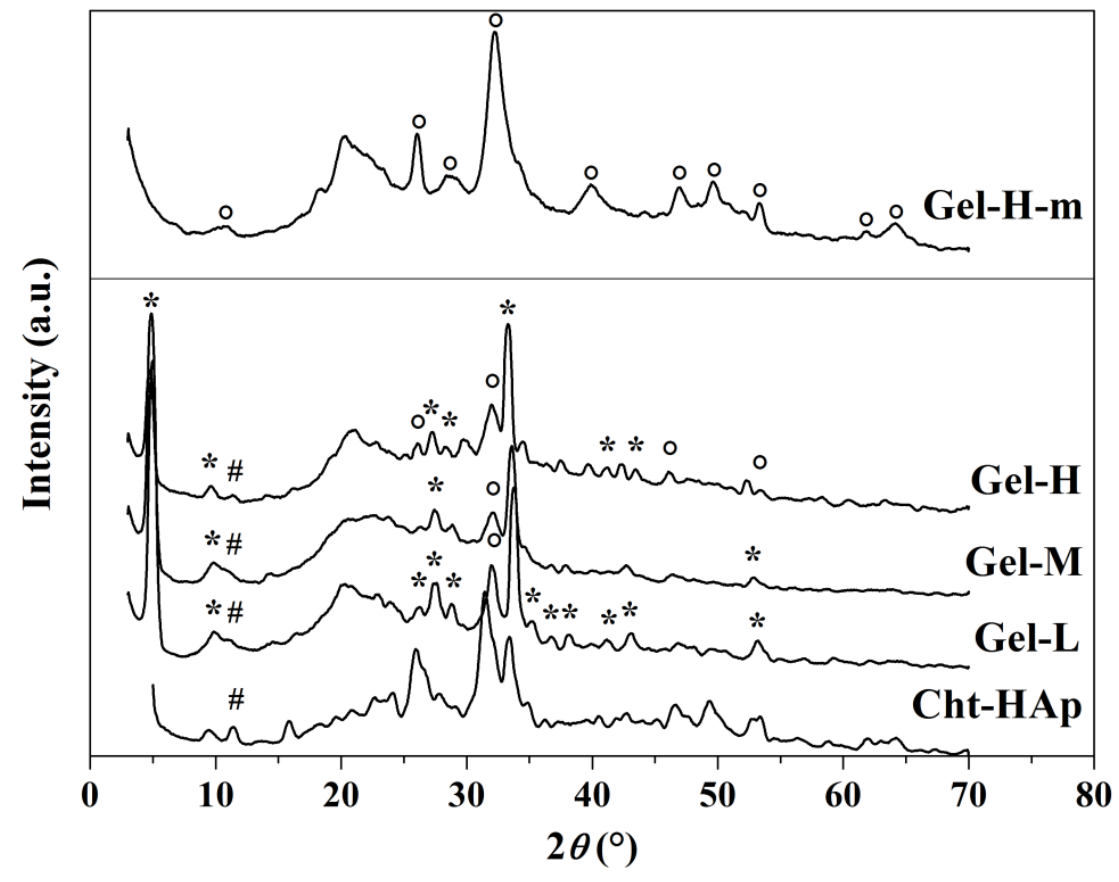

Figure 2. Characterization of prepared systems. a) FTIR spectra: phosphate bands characteristic for hydroxyapatite lattice are visible in spectra of starting suspension (Cht-HAp) and crosslinked hydrogels (Gel-L, Gel-M, Gel-H and Gel-H-m); b) XRD patterns: the patterns are shifted vertically for better clarity. Characteristic HAp (ICDD 9-432) diffraction maxima are depicted as $\left({ }^{\circ}\right)$, while OCP (ICDD 11-0293) as $\left(^{*}\right)$ and DCPD (ICDD 79-0423) as (\#). 

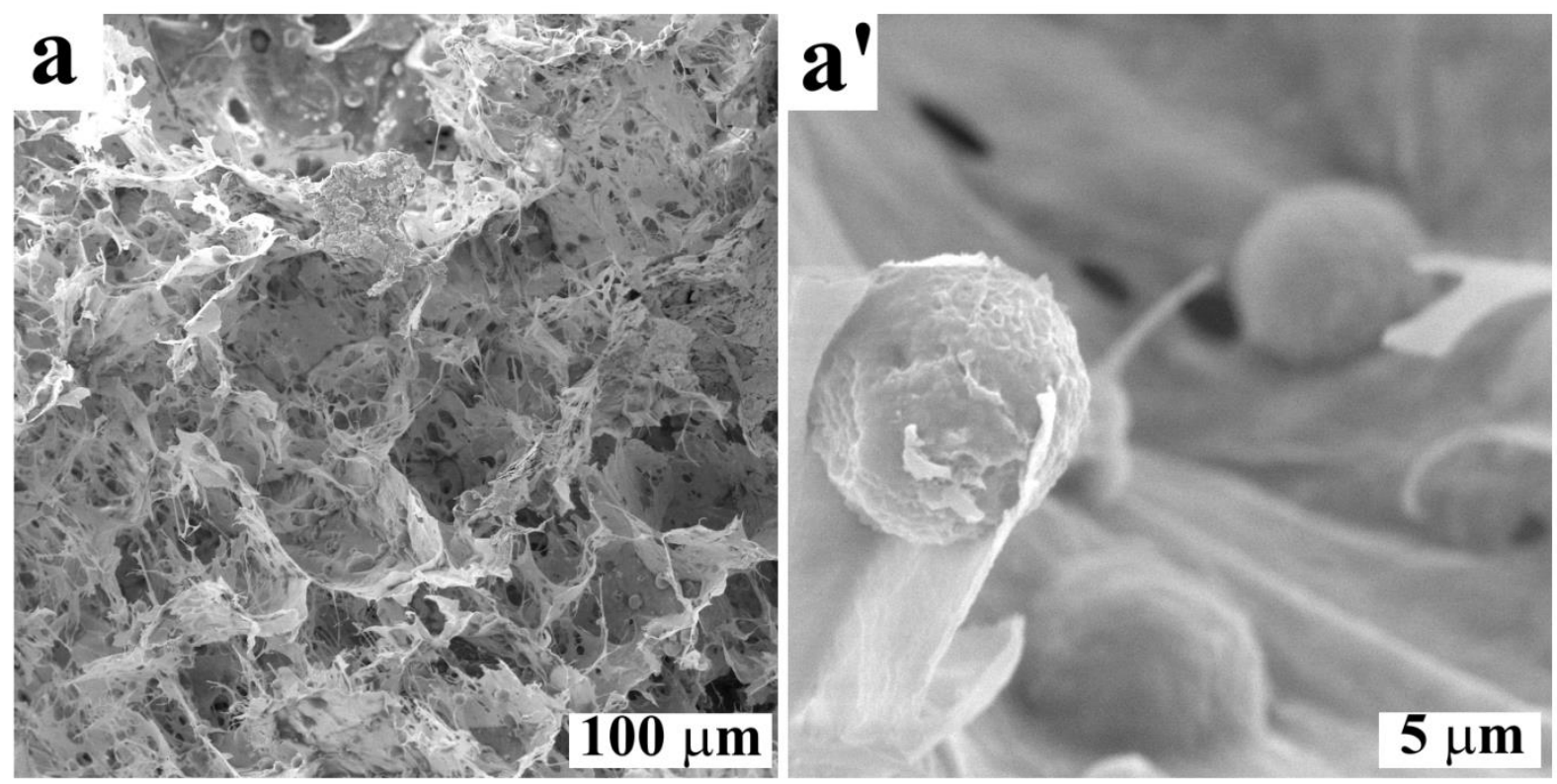

Figure 3. Microscopic imaging of crosslinked Gel-H-m hydrogel. a) 500x; a') 8000x of magnification. 
a)

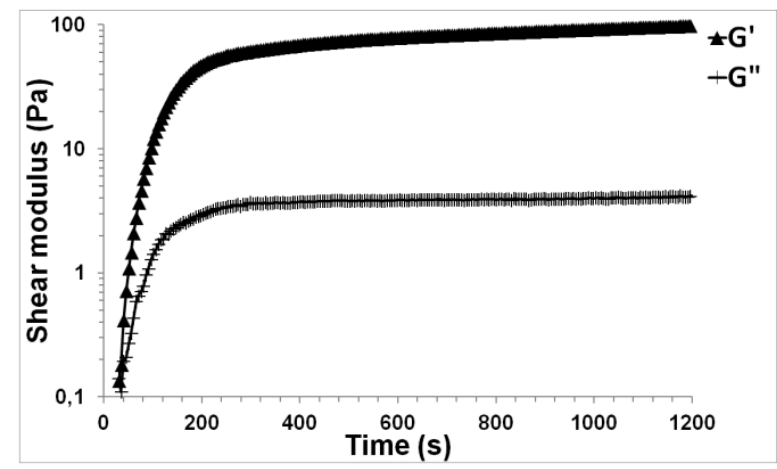

c)

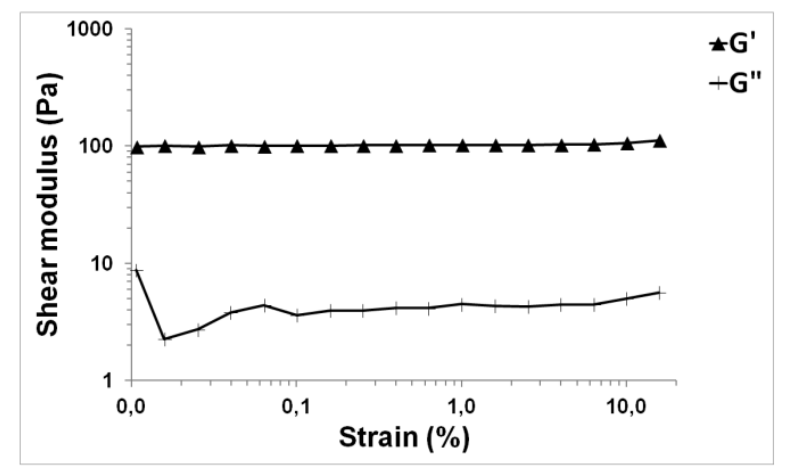

b)

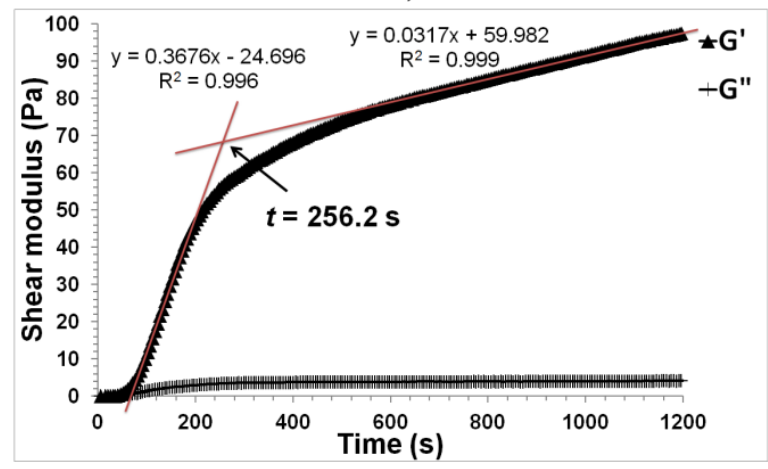

d)

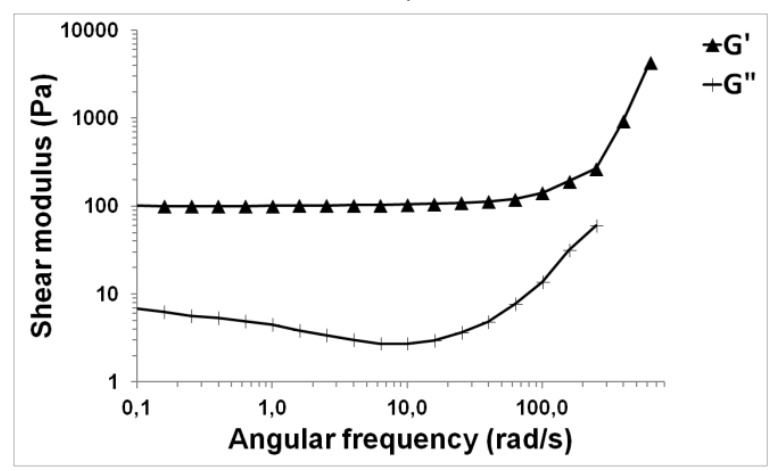

Figure 4. Rheological characterization of Gel-H-m hydrogel at $37^{\circ} \mathrm{C}$. Gel formation was monitored by time sweeps. a) and b) Storage $\left(G^{\prime}\right)$ and loss $\left(G^{\prime \prime}\right)$ modulus as a function of time (a) A semilogarithmic plot; b) Estimation of the gelation time). The linear viscoelastic limit on physically crosslinked hydrogel was determined by strain sweep at a frequency of $0.2 \mathrm{~Hz}$. c) Amplitude sweep data showing storage $\left(G^{\prime}\right)$ and loss $\left(G^{\prime \prime}\right)$ modulus as a function of strain. d) Frequency sweep data at a constant strain of $2 \%$. The curves represent average values obtained from four individual measurements. The error bars were excluded from the final graphs for the sake of clarity. Relative standard deviation of storage and loss modulus obtained in time sweep, strain sweep and frequency sweep tests is $\pm 12.96, \pm 8.68, \pm 8.31$ and $\pm 12.07 \pm 13.79 \%, \pm 6.00$, respectively. 


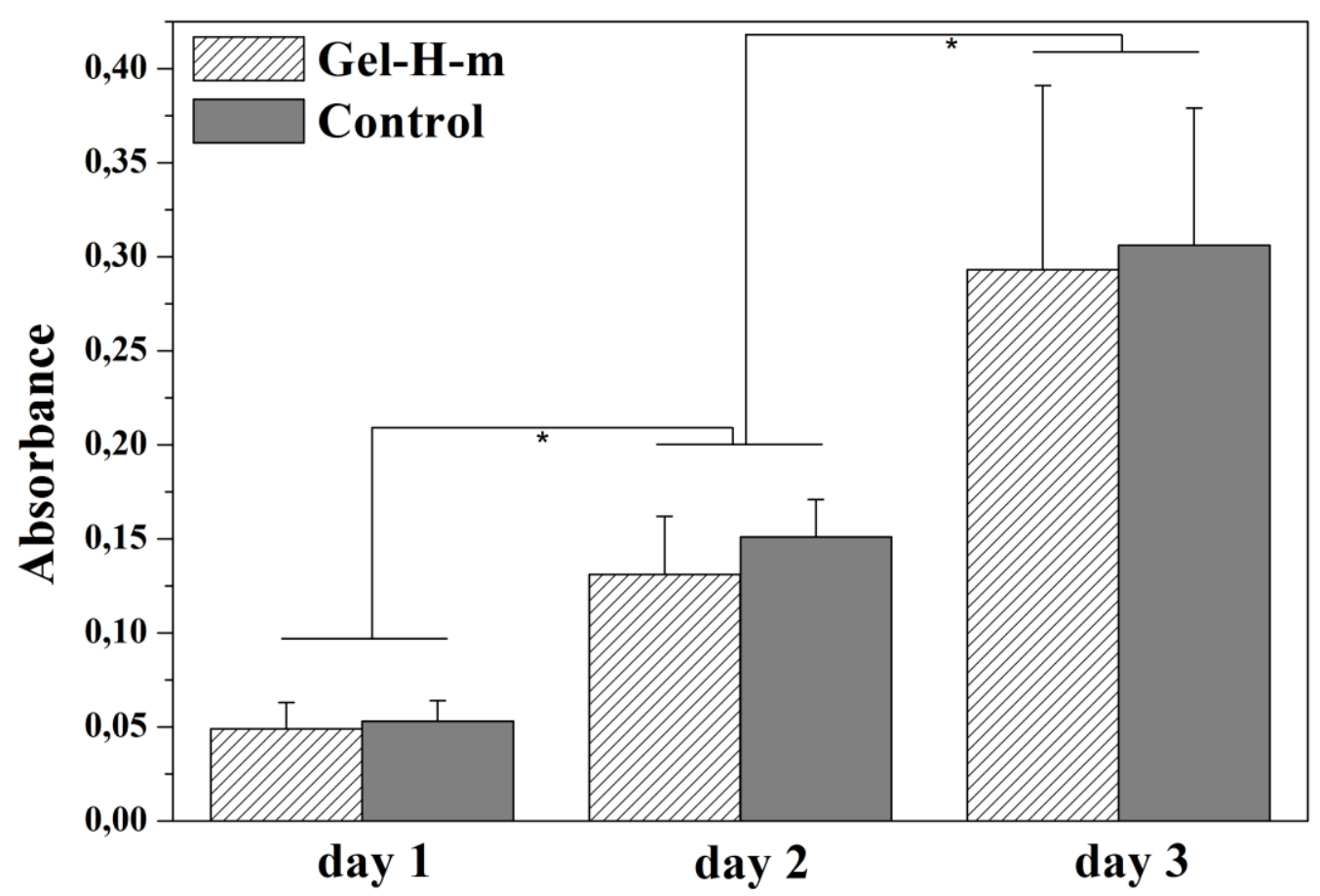

Figure 5. Cytotoxicity of supernatant of crosslinked Gel-H-m hydrogel. The viability of mouse fibroblasts cells at 1,2 and 3 days of culture expressed by the absorbance. The basal $\alpha$ MEM medium was used as a negative control. The significant difference between two groups $(*): p<0.05$. 

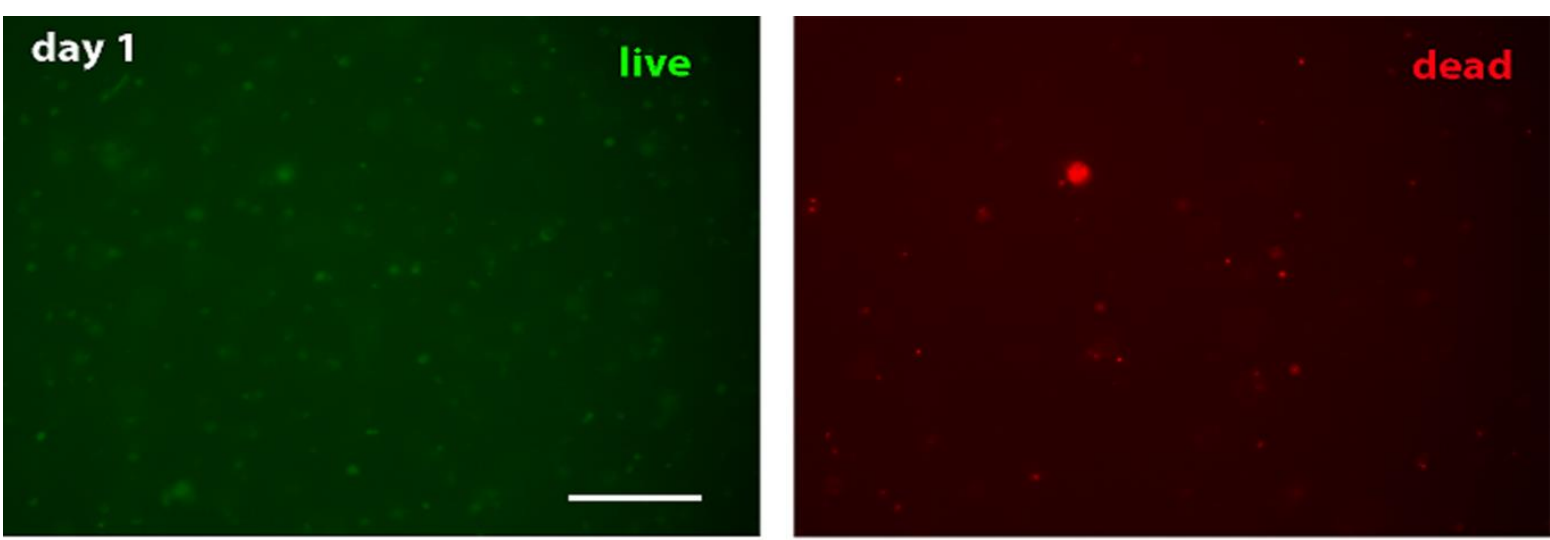

day 2

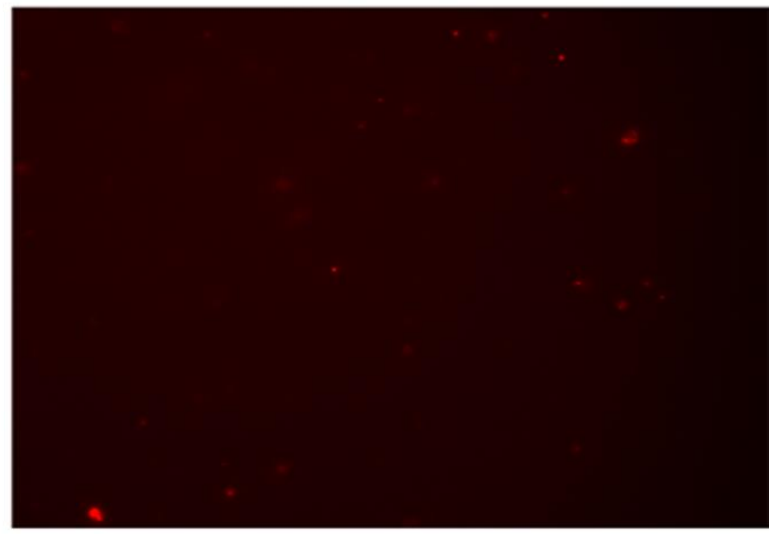

day 3

day 7 
Figure 6. Live dead staining of encapsulated cells. The cell viability and distribution within crosslinked Gel-H-m hydrogel after 1, 2, 3 and 7 days of culture. Live cells are stained in green, dead cells are stained in red. Scale bar: $200 \mu \mathrm{m}$. 
Table 1. The composition of crosslinked chitosan-hydroxyapatite/ $\mathrm{NaHCO}_{3}$ hydrogels. Volume of crosslinked hydrogel $(V)$, calculated weight $(m)$ of chitosan, $\mathrm{HAp}$ and $\mathrm{NaHCO}_{3}$ in crosslinked hydrogel, calculated concentration $(\gamma)$ of gelling agent per volume of crosslinked hydrogel.

\begin{tabular}{lllllll}
\hline Samples & $\begin{array}{l}V(\text { gel }), \\
\mathbf{m L}\end{array}$ & $\begin{array}{l}\boldsymbol{m}(\mathrm{Cht}), \\
\mathbf{m g}\end{array}$ & $\begin{array}{l}\boldsymbol{m}(\mathrm{HAp}), \\
\mathbf{m g}\end{array}$ & $\begin{array}{l}\boldsymbol{m}(\mathbf{N a H C O}), \\
\mathbf{m g}\end{array}$ & $\begin{array}{l}\gamma\left(\mathrm{NaHCO}_{3}\right), \\
\mathbf{m g} / \mathbf{m L}\end{array}$ & $\begin{array}{l}\text { Solvent for } \\
\text { gelling agent }\end{array}$ \\
\hline Cht-HAp & 10 & 121.1 & 51.8 & 0 & 0 & - \\
Gel-L & 11.5 & 121.1 & 51.8 & 7.8 & 0.7 & water \\
Gel-M & 11.5 & 121.1 & 51.8 & 10.4 & 0.9 & water \\
Gel-H & 11.5 & 121.1 & 51.8 & 13.0 & 1.1 & water \\
\hline \hline Gel-H-m & 11.5 & 121.1 & 51.8 & 13.0 & 1.1 & $\alpha$-MEM \\
\hline
\end{tabular}


Table 2. The pH values of hydrogels (Gel-L, Gel-M, Gel-H): immediately after adding the gelling agent $\left(T=10^{\circ} \mathrm{C}\right)$ and after complete gelation $\left(T=37^{\circ} \mathrm{C}\right)$.

\begin{tabular}{lllll}
\hline & Cht-HAp & Gel-L & Gel-M & Gel-H \\
\hline $\mathbf{p H}\left(\mathbf{1 0}{ }^{\circ} \mathbf{C}\right)$ & - & 6.80 & 6.96 & 7.01 \\
$\mathbf{p H}\left(\mathbf{3 7}^{\circ} \mathbf{C}\right)$ & 5.88 & 7.33 & 7.29 & 7.28 \\
\hline
\end{tabular}

